\title{
Egg size variability and mating system in the marbled goby Pomatoschistus marmoratus (Pisces: Gobiidae)
}

\author{
Carlotta Mazzoldi, Carlo Poltronieri, Maria B. Rasotto*
}

Dipartimento di Biologia, Università di Padova, Viale G. Colombo 3, 35131 Padova, Italy

\begin{abstract}
The marbled goby Pomatoschistus marmoratus inhabits the Venetian lagoon, northern Adriatic Sea. We used both field and laboratory approaches to investigate the mating system and factors influencing egg size and number. Males nest in empty bivalve shells and provide parental care to eggs. Egg size showed wide variation $(\mathrm{CV}=11.5 \%)$ and was positively correlated with female size and parental male size, but negatively with the progression of the spawning season. Field data showed that larger males occupied larger nests and obtained more and larger eggs than smaller males. Laboratory experiments showed that larger females produced both more and larger eggs than smaller ones. The relationship between egg size and male and female sizes suggested the presence of size-assortative mating in this species. The presence of high environmental variability could select for the peculiar pattern of egg size variability observed in this population
\end{abstract}

KEY WORDS: Egg size $\cdot$ Gobiidae $\cdot$ Pomatoschistus marmoratus $\cdot$ Venetian lagoon Resale or republication not permitted without written consent of the publisher

\section{INTRODUCTION}

Size variability among eggs and young larvae is well known to occur in teleost fish at both inter- and intrapopulation levels (Chambers 1997). These differences in the initial sizes of young tend to be retained for at least several weeks, affecting swimming performance, the abilities to avoid predators, the size range of potential prey species and, consequently, the mortality rate during the earliest days of a fish's life (Chambers 1997). While little is known regarding the genetic origins of initial fish size, maternal phenotype and various environmental factors have been associated with patterns of egg and larval size, both among and within populations (Chambers 1997). The relationship between female and egg size can be diverse: egg size can increase or decrease with female size, it can peak at intermediate female sizes or it can increase with female size, but only among females of different ages

${ }^{*}$ Corresponding author. E-mail: rasotto@civ.bio.unipd.it
(Hislop 1988, Chambers 1997). Environmental variables such as season and latitude are known to influence egg size, which in turn, determines larval size at hatching (Miller et al. 1988, Chambers 1997). In particular, in several temperate spring-spawning species (species that spawn between the late winter and late summer), a decrease of egg size over the reproductive season has been reported. Multiple factors are thought to underlie seasonal patterns in egg and larval size, either through direct effects on oogenesis (Solemdal 1967) or indirect effects on egg size in relation to the production cycle and availability or size of larval food (Ware 1975). Temperature has been suggested to indirectly affect egg size, because of its influence on oxygen concentration. Indeed, since large eggs have a smaller surface to volume ratio than smaller ones, the latter survive better in low oxygen concentrations (Beacham \& Murray 1985, Van den Berghe \& Gross 1989). As the season progresses, decreasing oxygen concentration (a consequence of increasing water temperature), could then favor the production of small eggs in temperate spawning species. In other temper- 
ate species the seasonal reduction in egg size appears more closely related to female status (i.e. age, size and condition, according to Chambers 1997) than it is to factors such as temperature or salinity (Chambers \& Leggett 1996).

In a recent study on the reproductive biology of several gobiid species in the Venetian lagoon, eggs of different sizes were found in the nests of the marbled goby Pomatoschistus marmoratus (Risso, 1810). P. marmoratus is a small-bodied fish reaching a maximum total length (TL) of $65 \mathrm{~mm}$ (Mazzoldi 1999), it is found througout the eastern Atlantic, Mediterranean, Black and Azov Seas and the Suez Canal, inhabiting sandy, inshore, shallow waters and sometimes brackish and hypersaline waters (Maccagnani et al. 1985, Mazzoldi $\&$ Rasotto 2001). During the reproductive season males build a nest by cleaning the inside of empty bivalve shells and covering the outside with sand (Gandolfi et al. 1991, Mazzoldi \& Rasotto 2001). They defend the nest and take care of the eggs laid by females on the upper valve, cleaning and fanning them until hatching (Gandolfi et al. 1991, Mazzoldi \& Rasotto 2001). Eggs are pear shaped and hang downwards from a chorion area, the micropilar region, presenting a layer of filaments (Mazzoldi 1999) (Fig. 1). In the Venetian lagoon, $P$. marmoratus shows an annual life cycle, with a maximum recorded age of 17 mo (Mazzoldi \& Rasotto 2001). Its breeding season, lasting from April to October, exhibits 2 different peaks, from April to the middle of July and from the middle of August to the end of September. During the first spawning peak, breeding individuals vary widely in body size, while during the second spawning peak, only small ones, hatched during the first spawning peak, are found breeding. Females appear to be multiple spawners, and the presence of male alternative mating tactics can be excluded (Mazzoldi \& Rasotto 2001).

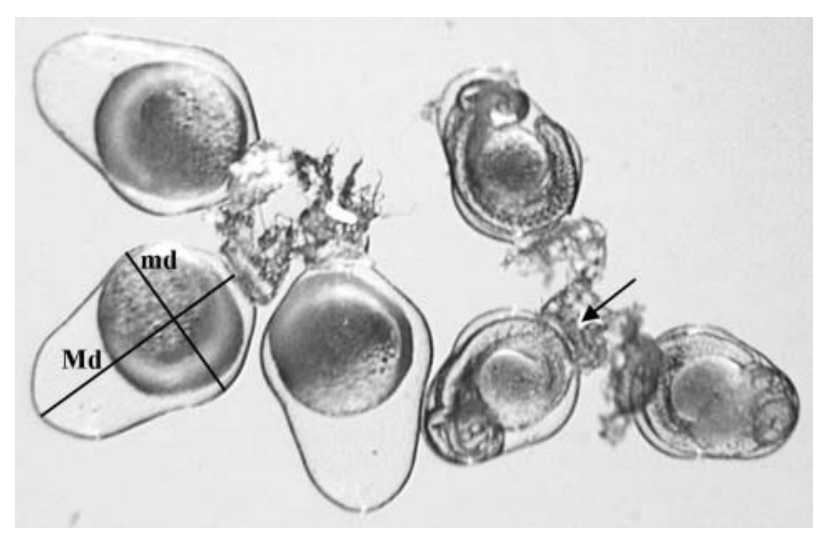

Fig. 1. Pomatoschistus marmoratus. Eggs of different sizes and developmental stages $(\mathrm{Md}$, major diameter; md, minor diameter; arrow, micropilar region surrounded by filaments).$\times 25$
The present study, conducted both in the field (the Venetian lagoon) and in the laboratory, aimed to document the variability in egg size and to possibly evaluate the major factors influencing this variability by analyzing: (1) nests and nesting male characteristics, (2) egg number and size (per nest), (3) female/egg size relationship, (4) duration of embryonic development, and (5) egg/larval size relationship.

\section{MATERIALS AND METHODS}

The study was performed during the marbled goby Pomatoschistus marmoratus breeding seasons of 1997 and 1998. Field data were collected in a shallow sandy area in the southern Venetian lagoon, the Lombardo bank. Specimens for laboratory experiments were collected in the same area by SCUBA divers using hand nets.

Field data. Field observations were performed in order to collect information on nests, nesting male characteristics, egg number and size and larval size. Only males found inside nests containing developing eggs were considered as nesting. Nests and nesting males were collected simultaneously by SCUBA divers using hand nets. Male size (TL to the nearest $\mathrm{mm}$ ) was measured in the field with a ruler, and males were immediately released. A total of 94 nests were brought to the laboratory in order to measure: (1) nest surface in $\mathrm{cm}^{2}$ (estimated by tracing the nest edge to a transparent nylon sheet adherent to the inner surface and computing the area using AutoCAD LT software); (2) egg area (estimated by drawing egg mass edge); (3) percentage of nest occupied by eggs (computed as $100 \times$ egg area/nest surface; (4) egg density (number of eggs per $\mathrm{cm}^{2}$ of egg area, estimated by counting all the eggs inside a square of 0.5 $\times 0.5 \mathrm{~cm}^{2}$ under a stereomicroscope; from 1 to $7 \mathrm{den}-$ sity estimates were performed for each nest); (5) total egg number (egg density $\times$ egg area); (6) number of different developmental stages (estimated by counting the different developmental stages of the eggs inside each nest; see 'Embryological development'); and (7) egg size (for a sample of 10 to 90 eggs, at the same developmental stage, for 73 nests, major and minor diameters [Fig. 1] were measured under a stereomicroscope, using a calibrated eyepiece; precision: $0.026 \mathrm{~mm}$ ). To validate egg number estimation, all the eggs present in 25 nests were individually counted under a stereomicroscope. No differences between estimated number of eggs and number of counted eggs were found ( $t$-test for paired data: $t=$ $-1.44, \mathrm{p}>0.05, \mathrm{~N}=25$ ), and the correlation between them was high (Pearson's correlation coefficient: $\mathrm{r}=$ $+0.84, \mathrm{p}<0.001, \mathrm{~N}=25)$. 
Eggs found inside the 94 nests were reared in small tanks $(1 \mathrm{l})$ at a temperature of 19 to $22^{\circ} \mathrm{C}$ and, for 34 egg batches, a sample of 10 to 90 anaesthetized (MS222) larvae just after yolk absorption, was measured (standard length, SL) under a stereomicroscope, using a calibrated eyepiece. After measurement, larvae were released in the field. Larvae from some of the nests hatched during transportation to the laboratory: consequently, it was not possible to record all measures for these nests.

The nest surface and egg area of an additional 17 nests were estimated directly in the field. Those nests were marked with colored signs on the outer surface and put back on the sandy bottom together with the nesting male, which typically reentered the nest within a few minutes. Marked nests were checked during later sampling dates.

Laboratory data. Mating experiments were conducted in captivity in order to collect information on female fecundity and egg size. Males and females were recognized by sexually dimorphic genital papillae (Gandolfi et al. 1991) and kept separate in stock tanks provided with sandy bottom and artificial shelters. Seawater was renewed daily, and the temperature range was kept at 18 to $22^{\circ} \mathrm{C}$. Light regime followed natural conditions, and fishes were fed once a day with fresh black mussel meat. Experimental males, ranging in size from 31 to $58 \mathrm{~mm} \mathrm{TL}$, were kept individually in aquaria (26 l) with an artificial nest composed of a piece of PVC pipe, ranging in size from 12 to $49 \mathrm{~cm}^{2}$. Each nest was provided with an acetate sheet that could easily be removed in order to collect eggs. After $3 \mathrm{~d}$ of acclimatization, a ripe female was added to each aquarium. For each spawning the following data were recorded: (1) spawning duration; (2) female size (TL) and total weight (wt, to the nearest $0.01 \mathrm{~g}$ ); (3) egg area, egg density, egg number, egg and larval size, using the methods described in the 'Field data' section; and (4) relative fecundity of females (number of eggs released divided by wt of the female). Estimation of egg number was validated with the method used for field data. No difference between estimated number of eggs and number of counted eggs was observed ( $t$-test for paired data: $t=+0.81, \mathrm{p}>0.05, \mathrm{~N}=17$ ) and the correlation between them was high (Pearson's correlation coefficient: $r=+0.98, p<0.001, N=17$ ).

Embryological development. In order to use embryo developmental stage as a criterion to evaluate the number of egg batches present in natural nests (see 'Field data' section) 5 egg batches laid in aquarium spawning experiments were reared in 11 tanks. Each egg batch was split into 2 parts, and these subsamples were reared at 2 different temperature intervals, 18 to $20^{\circ} \mathrm{C}$ and 21 to $23^{\circ} \mathrm{C}$, according to the water temperatures recorded during the 2 breeding peaks of temper- ate marbled goby. Embryo features were recorded every $12 \mathrm{~h}$, until hatching, under a stereomicroscope. Developmental stages were assigned to 6 categories: (1) pre-neurulation, (2) post-neurulation, (3) eyes and somites developed, (4) ear vesicles developed and heartbeats, (5) completely pigmented eyes, developed gills and swim bladder and visible blood circulation, and (6) pigmented body and iridescent eyes (hatching larvae). A random sample of 20 eggs from each batch subsample was measured daily to check for variability in egg size during development.

Data analyses. Descriptive analyses are reported as mean \pm standard error (SE). Coefficient of variation (CV) was computed as $100 \times$ standard deviation of the mean (Sokal \& Rohlf 1997). Parametric or non-parametric tests were applied according to data distribution and test assumptions. Data were checked for normality using a Shapiro-Wilk test and, if not normally distributed, they were log transformed. Percentage data were converted to proportions and arc-sine transformed (Sokal \& Rohlf 1997). For stepwise multiple regression, $F$ for entry was set equal to $1, F$ for removal equal to 0.1 and the tolerance limit equal to 0.1. Data from different years were compared to check for differences. If no significant differences were found, data were pooled for the statistical analyses. Data were analyzed using STATISTICA 5.1.

\section{RESULTS}

\section{Field data}

A total of 111 nests were sampled in the 2 spawning seasons (Table 1). Male size correlated positively with nest surface (Pearson's correlation coefficient: $r=+0.80$, $\mathrm{p}<0.001, \mathrm{~N}=100$ ), egg area (Pearson's correlation coefficient: $r=+0.76, p<0.001, N=77$ ) (Fig. 2), and egg number (Pearson's correlation coefficient: $\mathrm{r}=+0.35$,

Table 1. Pomatoschistus marmoratus. Data on nests and parental males collected in the field

\begin{tabular}{|lccr|}
\hline & Mean $\pm \mathrm{SE}$ & Range & $\mathrm{N}$ \\
\hline Male TL $(\mathrm{mm})$ & $44.2 \pm 0.8$ & $28-62.5$ & 100 \\
Nest surface $\left(\mathrm{cm}^{2}\right)$ & $16.20 \pm 1.26$ & $5.25-91.5$ & 111 \\
Egg area $\left(\mathrm{cm}^{2}\right)$ & $8.11 \pm 0.55$ & $2.7-34.5$ & 84 \\
Percent of nest & & & \\
$\quad$ occupied by eggs & $56.4 \pm 1.8$ & $11.1-91.7$ & 84 \\
Egg density (no. cm & -2 \\
Egg number & $201.9 \pm 6.8$ & $99.3-272.0$ & 46 \\
Egg developmental stages & $1355 \pm 70$ & $412-2904$ & 54 \\
Egg major diameter $(\mathrm{mm})$ & $0.800 \pm 0.011$ & $0.660-1.050$ & 73 \\
Egg minor diameter $(\mathrm{mm})$ & $0.591 \pm 0.008$ & $0.490-0.820$ & 73 \\
Larval SL (mm) & $2.645 \pm 0.056$ & $2.270-3.530$ & 34 \\
\hline
\end{tabular}




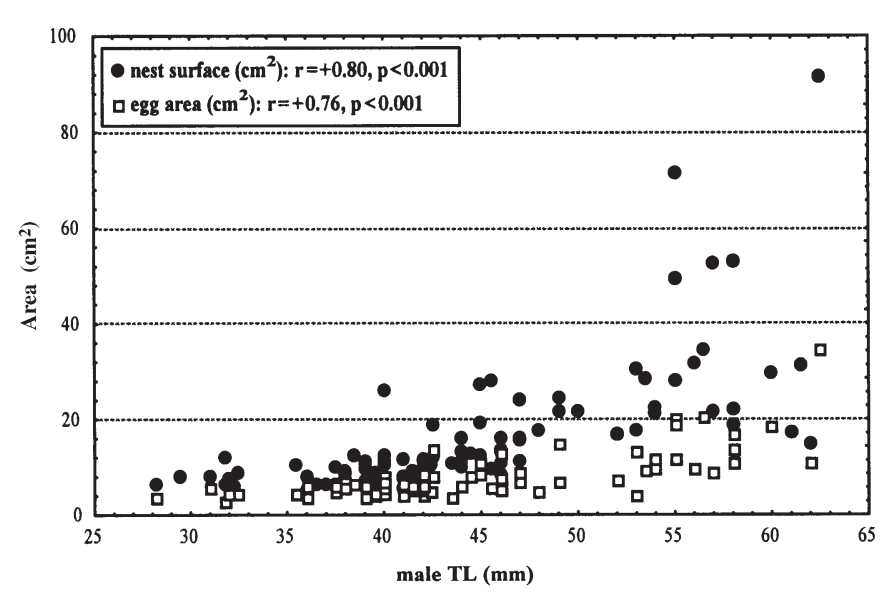

Fig. 2. Pomatoschistus marmoratus. Relationships between male size, nest surface and egg area

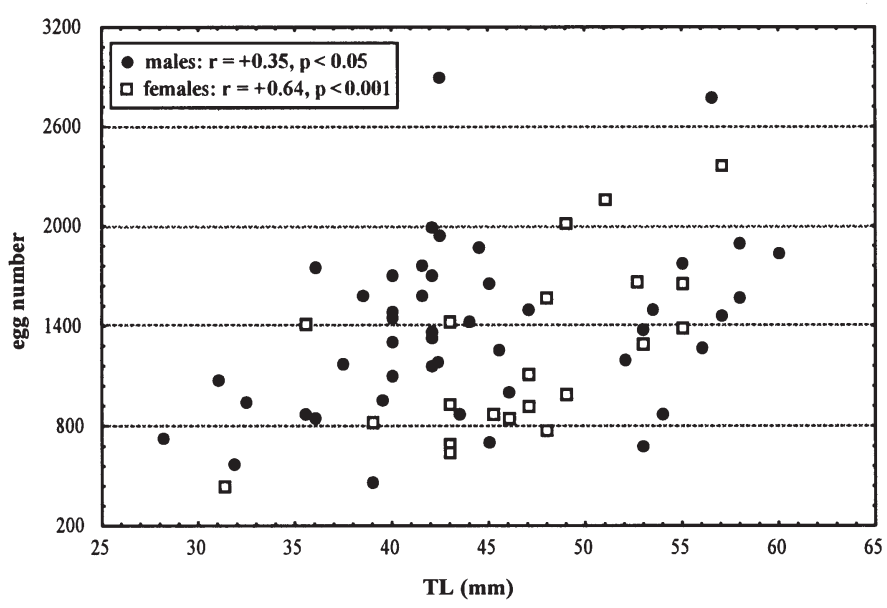

Fig. 3. Pomatoschistus marmoratus. Relationships between male size and number of eggs laid inside his nest (field data), and between female size and number of released eggs (data from aquarium experiments)

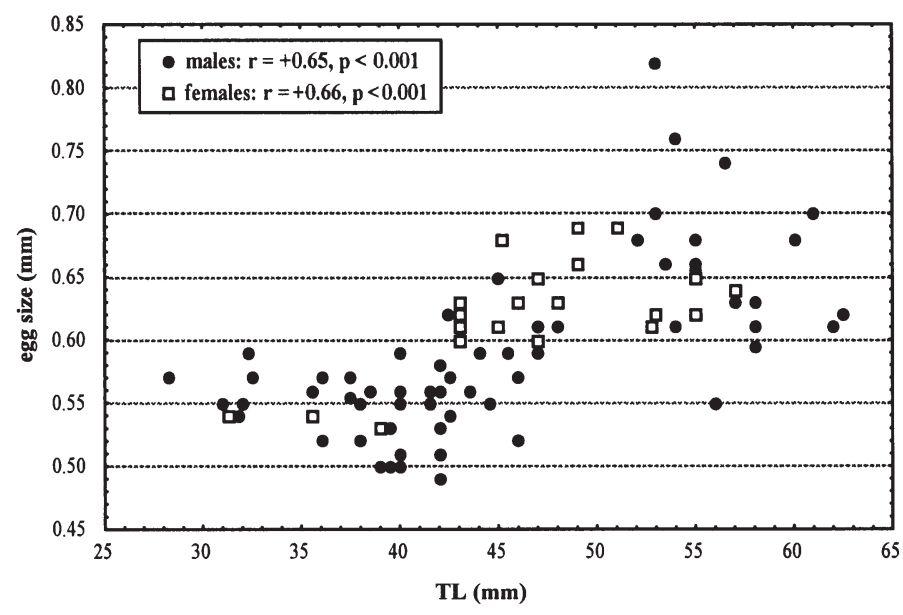

Fig. 4. Pomatoschistus marmoratus. Relationships between male size and size of eggs laid inside his nest (field data), and between female size and size of released eggs (data from aquarium experiments) $\mathrm{p}<0.05, \mathrm{~N}=47$ ) (Fig. 3). Egg area was also positively correlated with total nest surface area (Pearson's correlation coefficient: $\mathrm{r}=+0.81, \mathrm{p}<0.001, \mathrm{~N}=84$ ); however nest surface correlated negatively with percentage of nest occupied by eggs (Pearson's correlation coefficient: $\mathrm{r}=-0.51, \mathrm{p}<0.001, \mathrm{~N}=84$ ) and egg density (Pearson's correlation coefficient: $r=-0.76, p<0.001$, $\mathrm{N}=46$ ). To test if egg area was better predicted by male size or nest surface, we applied a stepwise multiple regression considering egg area as the dependent variable with male size and nest surface as independent variables. Both these variables were included in the analyses, but nest surface appeared more reliable than male size in predicting egg area (stepwise multiple regression: $F=106.45, \mathrm{p}<0.001, \mathrm{df}=2,74 ; \ln [$ egg area] $=0.55 \ln [$ nest surface $]+0.12$ male $\mathrm{TL}+0.001$; nest surface alone: $\mathrm{r}^{2}=0.73$, nest surface and male size: $\mathrm{r}^{2}=0.74$ ). A stepwise multiple regression in which egg number was used as the dependent variable with nest surface and male size as independent variables included only nest surface in the analysis (stepwise multiple regression: $F=8.04, \mathrm{p}<0.01, \mathrm{df}=1,45$; egg number $=341.71 \ln \left[\right.$ nest surface] $+510.46 ; r^{2}=0.15$ ). Male size did not correlate with the number of different egg batches inside the nest (Spearman's correlation coefficient: $r_{S}=+0.06, p>0.05, N=47$ ).

Male size correlated positively with egg size (Pearson's correlation coefficient: $\mathrm{r}=+0.65, \mathrm{p}<0.001, \mathrm{~N}=64$ ) (Fig. 4). Egg size showed wide variation, both for major (CV = $12 \%)$ and minor $(\mathrm{CV}=11.5 \%)$ diameters. Major and minor diameters correlated positively (Pearson's correlation coefficient: $\mathrm{r}=+0.91, \mathrm{p}<0.001, \mathrm{~N}=73$ ) and both correlated positively with larval size (Pearson's correlation coefficients: major diameter: $\mathrm{r}=+0.95, \mathrm{p}<0.001, \mathrm{~N}=34$; minor diameter: $\mathrm{r}=+0.96, \mathrm{p}<0.001, \mathrm{~N}=34$ ) (Fig. 5). In all egg size analyses the minor diameter value was used since it was the easiest to record and in addition it represented an indirect estimation of initial yolk size (Fig. 1).

Egg density correlated negatively with egg size (Pearson's correlation coefficient: $r=-0.77, p<0.001$, $\mathrm{N}=45$ ). A stepwise multiple regression, in which egg density was considered the dependent variable, while nest surface and egg size were the independent ones, included both variables in the analyses, but egg size was a better predictor of egg density than nest surface (stepwise multiple regression: $F=48.83, \mathrm{p}<0.001$, $\mathrm{df}=2,42 ; \ln [$ egg density $]=-1.74$ minor diameter $-0.20 \ln$ [nest surface] +6.82; egg size alone: $\mathrm{r}^{2}=0.59$, egg size and nest surface: $r^{2}=0.70$ ).

To check for a seasonal effect on egg size we considered only data collected between April and July, because the second spawning peak was studied only the second year and only few nests were found. Setting 1 April as Day 1, we found a negative correlation between egg size and date sampled (Pearson's correlation coeffi- 


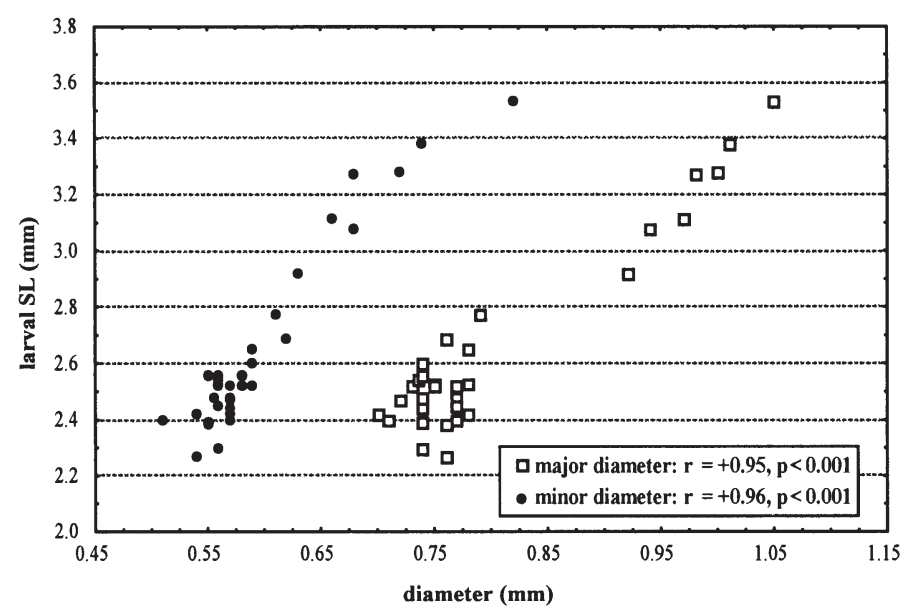

Fig. 5. Pomatoschistus marmoratus. Relationships between egg diameters and size of larvae (data from eggs collected in the field)

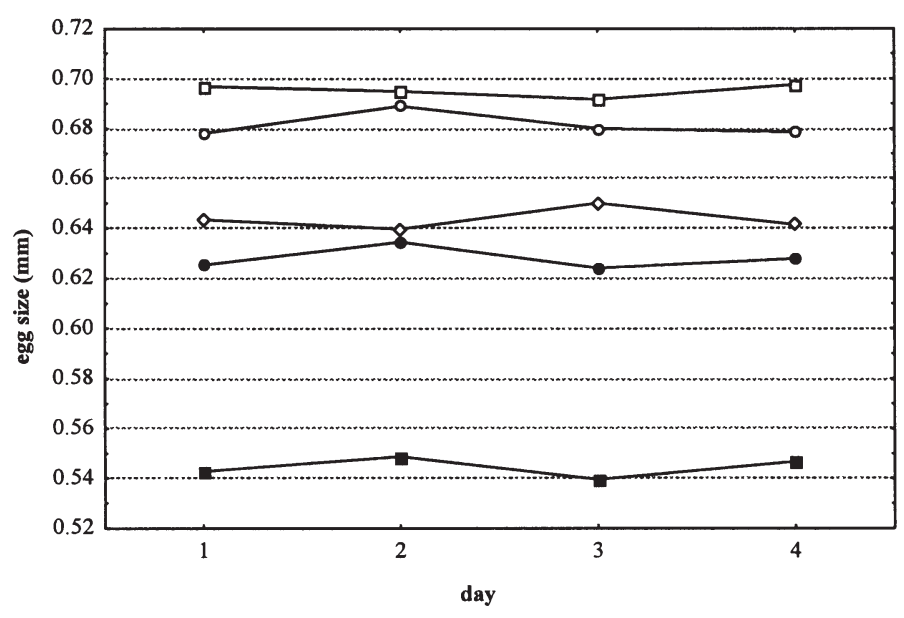

Fig. 6. Pomatoschistus marmoratus. Relationship between development and egg size (minor diameter) for 5 egg batches

cient: $\mathrm{r}=-0.35, \mathrm{p}<0.01, \mathrm{~N}=67$ ), while there was no correlation between the size of the parental male and date sampled (Pearson's correlation coefficient: $\mathrm{r}=+0.04, \mathrm{p}>$ $0.05, \mathrm{~N}=91$ ). A stepwise multiple regression, in which egg size represented the dependent variable, and male size and date were the independent ones, included both variables in the analyses, but male size better predicted egg size (stepwise multiple regression: $F=41.68, \mathrm{p}<0.001, \mathrm{df}=$ 2,55 ; minor diameter $=+0.70$ male $\mathrm{TL}-$ 0.35 date +0.36 ; male size alone: $\mathrm{r}^{2}=$ 0.48 , male size and date: $\mathrm{r}^{2}=0.60$ ).

Among the 17 marked nests only 5 were found in subsequent samplings. Nesting males were still inside 4 of these nests and remained until egg hatching; subsequently the nests were found empty.

\section{Laboratory data}

A total of 23 spawnings occurred in aquaria (Table 2). Female size was positively correlated with egg area (Pearson's correlation coefficient: $\mathrm{r}=+0.72, \mathrm{p}<$ $0.001, N=20$ ), number of released eggs (Pearson's correlation coefficient: $\mathrm{r}=+0.64, \mathrm{p}<0.001, \mathrm{~N}=21$ ) (Fig. 3) and egg size (Pearson's correlation coefficient: $\mathrm{r}=+0.66, \mathrm{p}<0.001, \mathrm{~N}=23$ ) (Fig. 4), but negatively with relative fecundity (Pearson's correlation coefficient: $r=-0.67, p<0.05, N=9$ ). Egg size was negatively correlated with egg density (Pearson's correlation coefficient: $\mathrm{r}=-0.52, \mathrm{p}<0.05, \mathrm{~N}=19$ ). Utilizing the April to July laboratory data, we found no correlation between female size and spawning date (Spearman's correlation coefficient: $r_{S}=-0.11, p>0.05, \mathrm{~N}=$ $22)$, while egg size correlated negatively with spawning date (Spearman's correlation coefficient: $r_{S}=$ $-0.47, \mathrm{p}<0.05, \mathrm{~N}=22$ ). A stepwise multiple regression, in which egg size was considered the dependent variable and female size and date the independent variables, included both variables in the analyses, but female size was a better predictor of egg size (stepwise multiple regression: $F=8.06, \mathrm{p}<0.01, \mathrm{df}=2,19$; minor diameter $=+0.53$ female $\mathrm{TL}-0.38$ date +0.49 ; female size alone: $r^{2}=0.31$, female size and date: $r^{2}=$ 0.46).

\section{Embryological development}

Larvae usually hatched in 4 to $5 \mathrm{~d}$, depending on rearing temperature and despite their size. No effect of development on egg size was observed; indeed, while there were differences among batches, we found no difference among developmental days in egg size (ANOVA - batches: $F=1052.36, \mathrm{p}<0.001$, df = 4,380; development: $F=1.065, \mathrm{p}>0.05$, df $=3 / 12$, interaction batch $\times$ development: $F=1.357, \mathrm{p}>0.05$, df $=12,380$ ) (Fig. 6).

Table 2. Pomatoschistus marmoratus. Data on aquarium spawnings

\begin{tabular}{|c|c|c|c|}
\hline & Mean \pm SE & Range & $\mathrm{N}$ \\
\hline Female TL (mm) & $46.6 \pm 1.3$ & $31.3-57.0$ & 23 \\
\hline Spawning duration & $2 \mathrm{~h} 6 \min \pm 14 \mathrm{~min}$ & $1 \mathrm{~h} 16 \min -3 \mathrm{~h} 41 \min$ & 9 \\
\hline Egg area $\left(\mathrm{cm}^{2}\right)$ & $8.21 \pm 0.80$ & $2.47-15.86$ & 20 \\
\hline Egg density (no. $\mathrm{cm}^{-2}$ ) & $148.7 \pm 7.2$ & $111.5-223.0$ & 19 \\
\hline Egg number & $1241 \pm 115$ & $440-2374$ & 21 \\
\hline Major diameter (mm) & $0.866 \pm 0.013$ & $0.690-0.950$ & 23 \\
\hline Minor diameter (mm) & $0.623 \pm 0.009$ & $0.530-0.690$ & 23 \\
\hline Larval SL (mm) & $2.768 \pm 0.103$ & $2.440-3.210$ & 8 \\
\hline $\begin{array}{l}\text { Relative fecundity } \\
\text { (no. of eggs/body wt) }\end{array}$ & $1689.7 \pm 241.6$ & $901.4-3380.9$ & 9 \\
\hline
\end{tabular}




\section{DISCUSSION}

\section{Mating system}

In the Pomatoschistus marmoratus population of the Venetian lagoon some males were found to simultaneously take care of egg batches laid by different females. Moreover, our evaluation of different developmental stages could underestimate the real number of egg batches present inside a nest, since only batches laid within an interval of at least $12 \mathrm{~h}$ were distinguished. These observations indicate that males are polygynous. Larger males appear to select larger nests, obtaining a higher number of eggs compared with smaller ones. Male marbled gobies, as observed in other small-bodied goby species (Kvarnemo 1995), appear to choose nests according to their own body size, despite the abundance of available nests of different sizes in the study area (Mazzoldi \& Rasotto 2001). As suggested for the sand goby Pomatoschistus minutus, the preference shown by marbled goby males for particular nest sizes could be related to their ability to defend the nest (Kvarnemo 1995) and/or to female choice (Lindström 1992). Our data on marked nests suggest that marbled goby males do not remain in the same nest through different spawning events (a male spawning event may include 1 or more egg batches laid consecutively, within a time interval of few days). They leave the nest after egg hatching and either spend a period feeding or change nests.

A wide variability in egg size has been found in the population of marbled goby. Egg size appears to correlate with both female and male size, suggesting sizeassortative mating. In the following sections we discuss size-assortative mating and egg size variability in this population.

\section{Size-assortative mating}

Size-assortative mating in teleost species has often been associated with monogamous mating systems (e.g. in gobies: Reavis 1997), but is less common in polygynous ones. In a size-assortative mating situation both sexes can be choosy: individuals prefer mates of similar or larger size, with larger individuals being more selective. Male choice is usually towards larger females, with female fecundity being positively correlated with female size (Bagenal 1966). Considering that, in the marbled goby, larger males have more space available in their nests than smaller ones and thus could receive additional egg batches, male choice for larger females seems unlikely. In addition, spawning is not limited to a narrow temporal interval that might constrain the number of mates a male could have (Mazzoldi pers obs).

Female preference for larger males is quite common in teleost fishes (Kodric-Brown 1990) and has been reported also in gobies (Bisazza et al. 1989, Lindström 1992). If all females prefer large males in the marbled goby, we would not expect size-assortative mating, because large males have empty spaces in their nests, so they could receive egg batches also from small females. Small females could avoid spawning with large males because of male cannibalistic tendency or violent courtship (Downhover et al. 1983, Marconato \& Bisazza 1988), but this hypothesis does not seem to apply to the marbled goby, since aggressive behaviors towards females have never been observed. On the contrary, egg cannibalism by parental males could be a factor influencing the size-assortative pattern of this species. Indeed male cannibalism on eggs has been observed in the marbled goby (Mazzoldi pers. obs.), as in several other species with parental care. In pomacentrid species with male parental care, filial cannibalism appears to preferentially affect smaller egg batches (Petersen \& Marchetti 1989, Petersen 1990). In the marbled goby this may result in small females avoiding mating with large males because of the increased risk of the male cannibalizing their smaller egg batch. Small males on the other hand may be less likely to cannibalize, since they only obtain eggs from small females, as supported by the absence of large eggs in small males' nests.

\section{Egg size variability}

Egg size varies more in Pomatoschistus marmoratus ( $\mathrm{CV}=11.5 \%$ for the minor diameter) than in 56 species belonging to 18 families (Chambers \& Leggett 1996), in which egg size variation never exceeded $8 \%$ and was $<4.6 \%$ in most. In the marbled goby, egg size is positively correlated with larval size. Both field and laboratory data indicate that 2 major factors affect egg size: time of season and female size. However, the latter, as shown by multiple regression analyses, has a stronger influence on egg size variability than the former.

As in several temperate fish, in the marbled goby egg size decreased significantly as spawning season progressed. This seasonal trend in egg size does not appear, as suggested for other species (Chamber 1997), to be caused by a differential reproductive timing of females of different size and/or a progressive decrease in oxygen concentration. Indeed Pomatoschistus marmoratus is an annual species, and females in a wide range of sizes are ripe during the whole first spawning peak, in which egg size varies most. Moreover, nesting males ventilate their eggs directly, pro- 
viding oxygen to developing embryos. Instead, more important in affecting egg size in this population could be a temperature influence on the vitellogenesis processes, as well as poor female condition during the season, or the availability and size of larval food.

Despite seasonal influences, the major factor affecting egg size variability appears to be maternal size. The relation between female and egg size has been hypothesized to be constrained by morphological or physiological traits (Smith \& Fretwell 1974, Bernardo 1996, Sinervo 1999), but such a constraint has never been demonstrated in fish (Duarte \& Alcaraz 1989, Elgar 1990). Another hypothesis, related to female phenotype, is that small females invest in eggs that are suboptimal in size because a female's lifetime reproductive success would be diminished by the greater current investment in a larger young. This hypothesis appears unlikely for a species like Pomatoschistus marmoratus, with a short life-span, a single reproductive season, production of a large number of eggs by females of all sizes, and in which different-size females allocate relatively the same energy to egg production, as suggested by the absence of a correlation between gonadal investment and female size (Mazzoldi \& Rasotto 2001).

The environment could influence the release of different-size eggs through either pre- or post-hatching effects. Nest characteristics, with respect to oxygen concentration, might represent a patchy environment in which different optimal egg sizes could coexist (Van den Berghe \& Gross 1989). In the marbled goby, larger eggs were laid in larger nests. In this species, nests are completely covered with sand (Mazzoldi 1999) and males can modulate water flow inside the nest, leaving larger entrances when oxygen concentration is low (Jones \& Reynolds 1999). In addition larger eggs did not appear to be spaced out more in larger nests, as would be expected if they had a higher oxygen requirement, given also that larger nests usually have larger empty surfaces. Consequently, in this species, nest oxygen availability does not appear to represent a patchy environment for eggs. Also the possible differential fanning ability of different-size males appears unlikely to determine this egg size pattern. Indeed, since in gobiids fanning performances are known to correlate with male size (Lindström \& Hellström 1993) we should expect to find in other goby species the pattern of egg size variability and correlation between egg and male size observed in the marbled goby. Instead egg size variability related to male (and female) size has not been reported in other goby species. In addition, considering that, in the marbled goby, eggs of different size present a similar developmental time, it can be excluded that the relationships between egg and male size are related to the ability of larger males to perform longer parental care.
Environments inhabited by the marbled goby could also be heterogeneous with respect to factors that affect larval survival and consequently also influence egg size. The theory of optimal egg size (Smith \& Fretwell 1974), and the widespread assumption that larger larvae are always better than smaller ones, has been criticized by different authors, suggesting that different sizes of larvae or propagules might be better adapted to different environments (Capinera 1979, Kaplan \& Cooper 1984, Parker \& Begon 1986). An unpredictable environment would select a wide reaction norm of propagule size, favoring the production of different-size offspring that can cope with different environmental conditions (Capinera 1979, Crump 1981, Bernardo 1996, Mousseau \& Fox 1998). In teleost species larger larvae usually have higher survival rates (Beacham \& Murray 1985), more energy reserves, better performance in swimming, and are better at detecting food and predators (Miller et al. 1988), but they may also suffer higher probabilities of predator encounters and attacks than smaller ones (Litvak \& Leggett 1992, Pepin et al. 1992). Consequently, different environmental conditions, represented by factors such as differential food availability or differential predation pressure, could favor different sizes of eggs.

Variability in environmental conditions may cause egg size variability in the marbled goby. Indeed, the shallow waters where this species lives are characterised by fluctuations in temperature and salinity, possibly causing fluctuations in the abundance of different prey or predators of goby larvae (Mazzoldi 1999). Egg size variability has also been reported in a lagoon population of another annual goby species, the common goby Pomatoschistus microps (Bouchereau et al. 1991), which also has 2 spawning peaks during the breeding season (Bouchereau et al. 1993, Mazzoldi \& Rasotto 2001). The lack of 2 spawning peaks and of egg size variability in other studied populations of both $P$. marmoratus and P. microps (Bouchereau et al. 1991, Bouchereau \& Guelorget 1998, Mazzoldi \& Rasotto 2001) suggests an influence of environmental factors in the appearance of both these traits.

In conclusion, traditional explanations on the influence of season and maternal phenotype do not appear to exhaustively justify egg size variability in the marbled goby. Despite the possible indication of the role played by environmental variability, understanding of the origins of the observed pattern in egg size in this species requires new hypotheses and further investigation at both intra- and inter-specific levels. The results of this study on the marbled goby indicate that in future inter-specific comparisons, some aspects, such as size-assortative mating, egg shape and type of nest, appear to deserve attention. 
Acknowledgements. The authors are indebted to H. Hess and C. Petersen for helpful discussions on factors influencing egg size variability. S. Bevins and C. Petersen greatly improved a first version of the manuscript with their critical revisions; D. Bertotto has been supportive in rearing embryos and larvae. This work was supported by a M.U.R.S.T (Italian Ministry of University and Scientific and Technological Research) grant to M.B.R. All experiments performed in this study were conducted in accordance with Italian laws on animal keeping and protection.

\section{LITERATURE CITED}

Bagenal TB (1966) A short review on fish fecundity. In: Gerking SD (ed) The biological basis of freshwater fish production. Blackwell Scientific Publications, Oxford, p 89-111

Beacham TD, Murray CB (1985) Effect of female size, egg size, and water temperature on developmental biology of chum salmon (Oncorhynchus keta) from the Nitinat River, British Columbia. Can J Fish Aquat Sci 42:1755-1765

Bernardo J (1996) The particular maternal effect of propagule size, especially egg size: patterns, models, quality of evidence and interpretations. Am Zool 36:216-236

Bisazza A, Marconato A, Marin G (1989) Male competition and female choice in Padogobius martensi (Pisces, Gobiidae). Anim Behav 38:406-413

Bouchereu JL, Guelorget O (1998) Comparison of three Gobiidae (Teleostei) life history strategies over their geographical range. Oceanol Acta 21:503-517

Bouchereau JL, Quignard JP, Joyeux JC, Tomasini JA (1991) Stratégies et tactiques de reproduction de Pomatoschistus microps (Krøyer, 1838) et de Pomatoschistus minutus (Pallas, 1770) (Pisces, Gobiidae) dans le Golfe du Lion (France). Nids, déterminismes de la sédentarité et de la migration. Cybium 15:315-346

Bouchereau JL, Quignard JP, Joyeux JC, Tomasini JA (1993) Structure du stocks des géniteurs de la population de Pomatoschistus microps (Krøyer, 1838) (Gobiidae), dans la lagune de Mauguio, France. Cybium 17:3-15

Capinera JL (1979) Qualitative variation in plants and insects: effect of propagule size on ecological plasticity. Am Nat 114:350-361

Chambers RC (1997) Environmental influences on egg and propagule sizes in marine fishes. In: Chambers RC, Trippel LEA (eds) Early life history and recruitment in fish population. Chapman \& Hall, London, p 63-102

Chambers RC, Leggett WC (1996) Maternal influences on variation in egg sizes in temperate marine fishes. Am Zool 36:180-196

Crump M (1981) Variation in propagule size as a function of environmental uncertainty for three frogs. Am Nat 117:724-737

Downhover JF, Brown L, Pedersen R, Staples G (1983) Sexual selection and sexual dimorphism in mottled sculpins. Evolution 37:96-103

Duarte CM, Alcaraz M (1989) To produce many small or few large eggs: a size-independent reproductive tactic of fish. Oecologia 80:401-404

Elgar MA (1990) Evolutionary compromise between a few large and many small eggs: comparative evidence in teleost fish. Oikos 59:283-287

Gandolfi G, Zerunian S, Torricelli P, Marconato A (1991) I pesci delle acque interne italiane. Istituto Poligrafico e Zecca dello Stato, Rome
Hislop JR (1988) The influence of maternal length and age on the size and weight of the eggs and the relative fecundity of the haddock, Melanogrammus aeglefinus, in British waters. J Fish Biol 32:923-930

Jones JC, Reynolds JD (1999) Oxygen and the trade-off between egg ventilation and brood protection in the common goby. Behaviour 136:819-832

Kaplan RH, Cooper WS (1984) The evolution of developmental plasticity in reproductive characteristics: an application of the 'adaptive coin-flipping' principle. Am Nat 123: 393-410

Kodric-Brown A (1990) Mechanisms of sexual selection: insights from fishes. Ann Zool Fenn 27:87-100

Kvarnemo C (1995) Size-assortative nest choice in the absence of competition in males of sand goby, Pomatoschistus minutus. Environ Biol Fishes 43:233-239

Lindström K (1992) Female spawning patterns and male mating success in the sand goby Pomatoschistus minutus. Mar Biol 113:475-480

Lindström K, Hellström M (1993) Male size and parental care in the sand goby, Pomatoschistus minutus. Ethol Ecol Evol 5:97-106

Litvak MK, Leggett WC (1992) Age and size-selective predation on larval fishes: the bigger-is-better hypothesis revisited. Mar Ecol Prog Ser 81:13-24

Maccagnani R, Carrieri A, Frantoi P, Rossi R (1985) Osservazioni sulla struttura di popolazione e il ruolo trofico di tre specie di Gobidi (Knipowitschia panizzae, Pomatoschistus marmoratus, Pomatoschistus canestrini) in un ambiente del Delta del Po. Nova Thalassia 7 (Suppl 3):373-378

Marconato A, Bisazza A (1988) Mate choice, egg cannibalism and reproductive success in the river bullhead, Cottus gobio L. J Fish Biol 33:905-916

Mazzoldi C (1999) Studio comparativo della dinamica di accoppiamento e fecondazione in Teleostei ad uova demerse (A comparative study on mating behaviour and fertilization dynamic in demersal spawner teleosts). $\mathrm{PhD}$ thesis, Department of Biology, University of Padova, Italy

Mazzoldi C, Rasotto MB (2001) Extended breeding season in the marbled goby, Pomatoschistus marmoratus (Teleostei: Gobiidae), in the Venetian lagoon. Environ Biol Fishes 61: 175-183

Miller TJ, Crowder LB, Rice JA, Marchall EA (1988) Larval size and recruitment mechanisms in fishes: toward a conceptual framework. Can J Fish Aquat Sci 45:1657-1670

Mousseau TA, Fox CW (1998) The adaptive significance of maternal effects. Trends Ecol Evol 13:403-407

Parker GA, Begon M (1986) Optimal egg size and clutch size: effects of environment and maternal phenotype. Am Nat 128:573-592

Pepin P, Shears TH, de Lafontaine Y (1992) Significance of body size to the interaction between a larval fish (Mallotus villosus) and a vertebrate predator (Gasterosteus aculeatus). Mar Ecol Prog Ser 81:1-12

Petersen CW (1990) The occurrence and dynamics of clutch loss and filial cannibalism in two Caribbean damselfishes. J Exp Mar Biol Ecol 135:117-133

Petersen CW, Marchetti K (1989) Filial cannibalism in the cortez damselfish Stegastes rectifraenum. Evolution 43: 158-168

Reavis RH (1997) The natural history of a monogamous coralreef fish, Valenciennea strigata (Gobiidae) 2. Behavior, mate fidelity and reproductive success. Environ Biol Fishes 49:247-257

Sinervo B (1999) Mechanistic analysis of natural selection and a refinement of Lack's and William's principles. Am Nat 154(Suppl):26-42 
Smith CC, Fretwell SD (1974) The optimal balance between size and number of offspring. Am Nat 108:499-505

Sokal RR, Rohlf FJ (1997) Biometry. WH Freeman and Company, San Francisco

Solemdal P (1967) The effect of salinity on buoyancy, size and development of flounder eggs. Sarsia 29:431-442

Editorial responsibility: Otto Kinne (Editor),

Oldendorf/Luhe, Germany
Van den Berghe EP, Gross MR (1989) Natural selection resulting from female breeding competition in a Pacific salmon (coho: Oncorhyncus kisutch). Evolution 43:125-140

Ware DM (1975) Relation between egg size, growth, and natural mortality of larval fish. J Fish Res Board Can 32: 2503-2512

Submitted: August 3, 2001; Accepted: November 27, 2001 Proofs received from author(s): April 26, 2002 